\title{
Malformaciones congénitas: Nuevos desafíos para la Salud Pública
}

\section{Congenital Malformations: New Challenges For Public Health}

\author{
Rosanna Fonseca C.
}

Las malformaciones congénitas constituyen anomalías estructurales o funcionales, como trastornos metabólicos, que ocurren durante la vida intrauterina y se detectan durante el embarazo, en el parto o en un momento posterior de la vida. Constituyen una problemática que no podría denominarse emergente sino que más bien, ha adquirido una mayor visibilidad en los últimos años; se calcula que cada año 303.000 recién nacidos fallecen durante las primeras cuatro semanas de vida en el mundo debido a malformaciones congénitas $^{(1)}$

Desde el año 2000, en base a un decenio de grandes conferencias y cumbres de las Naciones Unidas, los dirigentes del mundo se reunieron para aprobar la Declaración del Milenio, y los países miembros se comprometieron en una nueva alianza mundial para reducir los niveles de pobreza extrema; el ODM 4 (objetivos del milenio) enfatizaba la reducción de la mortalidad en menores de 5 años. De esta manera, el Paraguay como país miembro de las Naciones Unidas puso en marcha las estrategias con el fin de disminuir las causas prevenibles de mortalidad en menores de 5 años; el impacto de las mismas se observaron en la variación registrada como principales causas de mortalidad en este grupo etario. En el año 2000 las causas de mortalidad en $<5$ años en orden descendente eran: $1^{\mathrm{o}}$ Neumonia, $2^{\mathrm{a}}$ Diarrea, 3 $3^{\text {a }}$ Causas externas, $4^{-a}$ Septicemia, 5 Tumores, 6 $6^{\mathrm{a}}$ Malformaciones congénitas; casi 20 años después según reportan las estadísticas vitales del Ministerio de Salud Pública y Bienestar Social,
MSPyBS, las causas de mortalidad para la franja etaria referida es cuanto sigue: $1^{\circ}$ Lesiones debidas al parto, $2^{\circ}$ Malformaciones congénitas, $3^{\circ}$ Causas externas, $4^{\circ}$ Infecciones del recién nacido, $5^{\circ}$ Prematuridad, $6^{\circ}$ Neumonia. ${ }^{(1)}$

Se puede manifestar, fundamentado en lo expresado arriba, que en casi 2 décadas, en nuestro país, las malformaciones congénitas pasan de ser la sexta causa a la segunda causa de mortalidad en $<5$ años; en algunos países constituye la primera causa. Las anomalías congénitas pueden ocasionar discapacidades crónicas con un gran impacto en los afectados, sus familias, los sistemas de salud y la sociedad. Ante esta realidad, en el año 2010 la Asamblea Mundial de la Salud adoptó una resolución sobre los defectos de nacimiento, y solicitó a todos los Estados miembros que fomentaran la prevención primaria y la salud de los niños con malformaciones congénitas, mediante el desarrollo y fortalecimiento de: registros, vigilancia, conocimientos, investigación, diagnóstico y prevención.

En el Paraguay, en el año 2007, el punto de partida del proceso de detección de anomalías fue la implementación del Programa de Prevención de la Fibrosis quística y del Retardo Mental. Se estableció el Test del Piecito gratuito y obligatorio para toda la población. Posteriormente por medio de la labor encomiable del grupo de profesionales liderado por la Dra. Marta Ascurra, en el año 2015, por resolución ministerial se crea el Programa Nacional de Prevención de Defectos Congénitos. Dicho

1. Ministerio de Salud Pública y Bienestar Social, Hospital Materno Infantil San Pablo, Centro de Especialidades Pediátricas. Asunción. Paraguay.

Correspondencia: Rosanna Fonseca C. Correo: rosannafonseca74@gmail.com DOI: https://doi.org/10.31698/ped.45012018001 
programa surge ante la necesidad de contar con una instancia que se ocupe de la prevención y atención de los pacientes con defectos congénitos. También se establece la notificación obligatoria de pacientes con estas noxas y se genera una red de servicios y profesionales con el fin de facilitar el diagnóstico, tratamiento, seguimiento de los pacientes y además de la contención de las familias. ${ }^{(2,3)}$

Por otro lado, es sabido que de alrededor del $50 \%$ de los defectos congénitos no es posible asignarle una causa específica; sin embargo, se han identificado algunas de las causas o factores de riesgo. Actualmente, se consideran que las mismas un origen genético, infeccioso o ambiental. ${ }^{(4,5,6)}$

La identificación de factores de riesgo prenatales como antecedentes familiares o de un hijo previo con malformaciones congénitas, la falta de suplemento de ácido fólico antes y/o durante el embarazo, la exposición materna a plaguicidas entre otros, constituye un componente fundamental para la consejería y por ende planificación del embarazo y/o nacimiento del niño; el articulo de Ojeda L, y col, publicado en el presente numero de la revista, establece la importancia estadística de esto. ${ }^{(4)}$

En el artículo mencionado las anomalías congénitas más frecuentemente detectadas fueron los defectos del tubo neural y las malformaciones cardiacas entre otras, dato que coincide a lo publicado en la literatura internacional.

La detección prenatal de la cardiopatía congénita, la hernia diafragmática, los defectos del tubo neural y de algunas otras anomalías, tiene gran importancia a la hora de determinar la vía de atención del parto, el nivel de complejidad de atención y el resultado del parto debido a la instauración temprana del

\section{REFERENCIAS}

1. OMS. Anomalias congénitas. Internet. OMS; 2015. Citado el 08 de junio de 2018. Recuperado a partir de: http://www.who.int/es/news-room/fact-sheets/detail/con genital-anomalies

2. MSPyBS. Historicas de Indicadores de Mortalidad tratamiento, así como para ofrecer asesoría a las mujeres gestantes de un niño con anomalías congénitas.

Algunas anomalías congénitas son posibles de prevenir y existen medidas de prevención fundamentales como la vacunación, la ingesta suficiente de ácido fólico y yodo mediante el enriquecimiento de alimentos básicos o el suministro de complementos así mismo los cuidados prenatales adecuados.

En este contexto la probabilidad de prevenir las malformaciones congénitas es del 50\% al 70\% del total de casos de espina bífida y anencefalia con la suplementación preconcepcional de ácido fólico. En el Paraguay, la fortificación de los alimentos con ácido fólico es obligatoria, mediante el Decreto № 20930 del Ministerio de Salud Pública y Bienestar Social del 24 de abril de 1998. Sin embargo según datos publicados por la INAN en el año 2015, mediante la vigilancia realizada, de 155 muestras de harina analizadas: $79 \%$ de las muestras no cumplían con los requerimientos establecidos y en casi el $8 \%$ de las muestras no era detectable el ácido fólico. ${ }^{(7,8,9)}$

El artículo que se publica en este número expone con claridad la problemática de las malformaciones congénitas y ante lo expuesto en esta editorial, podemos concluir que: Todas las instituciones y profesionales involucrados con esta situación no deben dejar de vigilar y velar por el cumplimiento de normativas establecidas; no deben dejar de sumar esfuerzos para prevenir lo que se puede prevenir por medio de la planificación; deben garantizar el tratamiento a los que se pueden tratar; y principalmente deben comprometerse y enfocarse a contener a las familias que tienen a un miembro de la misma solo le resta una muerte digna.

(INDIMOR). Internet. MSPyBS; 2000. Citado el 08 de junio de 2018. Recuperado a partir de: http://portal.mspbs.gov. py/digies/06-serie-historicas-indicadores-mortalidadindimor/

3. MSPyBS. Historicas de Indicadores de Mortalidad 
(INDIMOR). Internet. MSPyBS; 2016. Citado el 08 de junio de 2018. Recuperado a partir de: http://portal.mspbs.gov .py/digies/06-serie-historicas-indicadores-mortalidadindimor/

4. Ojeda L, Leite S. Factores de riesgo prenatales y su asociación a malformaciones congénitas en un Hospital Universitario de Referencia. Pediatr. (Asunción). 2018; 45(1).

5. Ascurra M. ¿Los agrotoxicos son teratogenicos?. Pediatr. (Asunción). 2007;34(2):109-10.

6. Benítez-Leite S, Macchi ML, Acosta M. Malformaciones congénitas asociadas a agrotóxicos. Pediatr. (Asunción). 2007;34(2):111-21

7. Ruoti Cosp M, Ruoti M, Rojas G, Ontano M, Rodriguez
S, Ascurra M. Conocimiento del consumo de ácido fólico y su relación con los defectos del tubo neural en mujeres puérperas. Mem. Inst. Investig. Cienc. Salud. 2016;14(1):57-63.

8. CDC, OPS, OMS. La prevención de los defectos del tubo neural con acido fólico. Internet. 2009; Citado el 15 de junio de 2018. Recuperado a partir de: http://www1.paho.org/ hq/dmdocuments/2009/Prevencion-de-defectos-tuboneural-con-acido-folico.pdf

9. Sánchez S, Masi C, Acosta J, Ayala C, Barreto P. Vigilancia del contenido del hierro y vitaminas del complejo $b$ en harina de trigo, en establecimientos elaboradores y fraccionadores - año 2015. Internet. 2015; Citado el 03 de junio de 2018. Recuperado a partir de: http://www.inan.gov.py/site/?page_id 